\title{
Suitability of the test results of micropitting tests acc. to FVA 54/7 for modern practical gear applications
}

\author{
Nadine Sagraloff ${ }^{1}$ (D) $\cdot$ Thomas Tobie $^{1} \cdot$ Karsten Stahl $^{1}$ \\ Received: 26 March 2021 / Accepted: 17 June 2021 / Published online: 9 July 2021 \\ (c) The Author(s) 2021
}

\begin{abstract}
A high load carrying capacity regarding micropitting is requested in many modern gear applications.

The lubricant used has a great influence on the micropitting resistance of a gear-lubricant-system. As a result, it is highly recommended that a lubricant with a sufficient micropitting load-carrying capacity be used to avoid micropitting. Lubricants usually contain additives, which also have a strong effect on micropitting load-carrying capacity depending on operating temperature. As a result, the load-carrying capacity of gear lubricants cannot be determined theoretically and has to be determined by physical testing.

A well-established test procedure to determine load-carrying capacity with regard to micropitting is the FVA/FZG-micropitting test according to FVA 54/7, which is also the basis of the recently published standard DIN 3990-16. This test method was defined about 30 years ago with standardized test gears, which differ from gears commonly used in modern applications. Therefore, the practicability of the test method needs to be reviewed and the suitability of the test results for modern practical gear applications needs to be verified.

For this purpose, screening tests were conducted with case-hardened gears of materials $16 \mathrm{MnCr} 5$ and $18 \mathrm{CrNiMo} 7-6$ to investigate the influence of the material on the results of the micropitting test. Additionally, the influence of test gears designed under consideration of practical applications on the test results was comprehensively examined. For this purpose, the micro-geometry (flank modifications), macro-geometry (helical gears) and grinding method (profile grinding) were altered.

The results show that the results of the micropitting test according to FVA 54/7 with standard test gears made of $16 \mathrm{MnCr} 5$ can be applied to gears with the material, micro- and macro-geometry as well as grinding methods used commonly in practical applications. This paper presents and summarizes the results of these experimental investigations.
\end{abstract}

\section{Eignung der Ergebnisse des Graufleckentests nach FVA 54/7 für moderne Getriebeanwendungen}

\section{Zusammenfassung}

In vielen modernen Getriebeanwendungen wird eine hohe Graufleckentragfähigkeit gefordert. Die Tragfähigkeit wird hierbei maßgeblich durch den verwendeten Schmierstoff beeinflusst. Um Graufleckenbildung zu vermeiden, ist es empfehlenswert einen Schmierstoff mit ausreichend hoher Graufleckentragfähigkeit zu verwenden. Schmierstoffe enthalten meist Leistungsadditive, welche die Graufleckentragfähigkeit in Abhängigkeit von der Betriebstemperatur stark beeinflussen. Die Tragfähigkeit dieser Schmierstoffe kann daher nicht theoretisch bestimmt und muss durch experimentelle Prüfung ermittelt werden.

Nadine Sagraloff

sagraloff@fzg.mw.tum.de

Thomas Tobie

tobie@fzg.mw.tum.de

Karsten Stahl

stahl@fzg.mw.tum.de

1 Gear Research Centre (FZG), Technical University of Munich (TUM), Boltzmannstraße 15, 85748 Garching near Munich, Germany 
Ein etabliertes Prüfverfahren stellt der FVA/FZG-Graufleckentest nach FVA 54/7, welcher als Grundlage der kürzlich veröffentlichten Norm DIN 3990-16 dient, dar. Diese Prüfmethode wurde vor ca. 30 Jahren mit standardisierten Prüfrädern definiert, welche sich von praxisüblichen Zahnrädern unterscheiden. Daher muss die Praxistauglichkeit des Prüfverfahrens überprüft und die Eignung der Prüfergebnisse für moderne praktische Getriebeanwendungen nachgewiesen werden.

Deshalb wurden Stichversuche mit einsatzgehärteten Zahnrädern der Werkstoffe 16MnCr5 und 18CrNiMo7-6 durchgeführt. Anhand dieser Stichversuche wurde der Einfluss des Werkstoffs auf die Ergebnisse des Graufleckentests untersucht. Zusätzlich wurden Untersuchungen zum Einfluss von praxisnahen Prüfräder auf die Prüfergebnisse durchgeführt. Die Prüfräder wurden hinsichtlich Mikro-Geometrie (Flankenmodifikationen), Makro-Geometrie (Schrägverzahnung) und Schleifverfahren (Profilschleifen) variiert.

Die Untersuchungen zeigen, dass die Ergebnisse des Graufleckentests nach FVA 54/7 mit Standardprüfrädern auf Zahnräder mit den in der Praxis üblichen Werkstoffen, Mikro- und Makro-Geometrien sowie Schleifverfahren übertragbar sind.

\section{Introduction}

Occurring micropitting of a certain intensity on gears may require the gears to be replaced in the gearboxes. This leads to high costs, particularly in industrial gear units and wind turbines. As a result, a high load-carrying capacity against micropitting is requested in many modern gear applications.

The main factors influencing micropitting are the condition of the surface of the mating contact partners, the operating conditions and the lubricant used [1]. As a result, using a lubricant with high micropitting resistance helps to reduce or avoid micropitting. Most gear lubricants contain additives. These additives have a strong effect on micropitting load-carrying capacity depending on the operating temperature. Therefore, the load-carrying capacity of gear lubricants cannot be determined theoretically and has to be determined by physical testing under suitable test conditions.

The micropitting resistance of lubricants can be determined by the widely used micropitting test according to FVA 54/7 [2]. The test procedure is described in FVA-Information Sheet 54/7 [2] and was published as DIN 399016 [3] in May 2020.

The micropitting test according to FVA 54/7 [2] was defined about 30 years ago. The standardized test gears used in the test method differ from gears now commonly used in modern applications. As a result, the influence of test gears designed under consideration of practical ap-
Fig. 1 Characteristic cracking on a driving pinion according to [5] and micropitted surface showing surface cracks [6] a

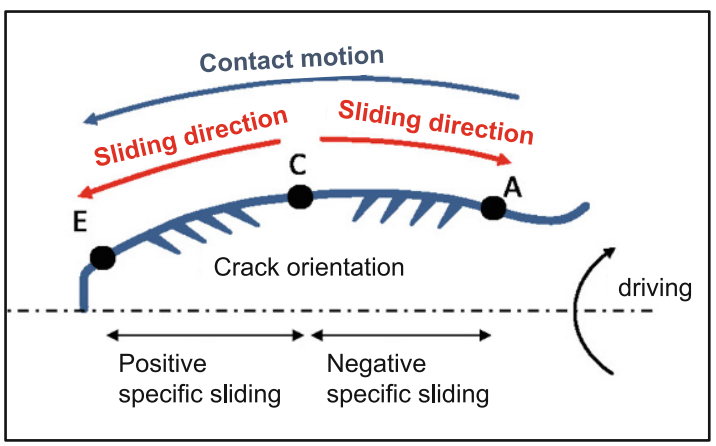

b

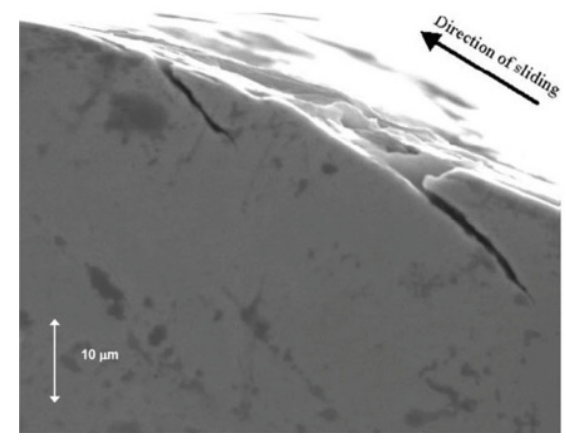

Fig. 2 Micropitted gear flank (a) and a $950 \times$ magnification of a micropitted flank [8] (b)
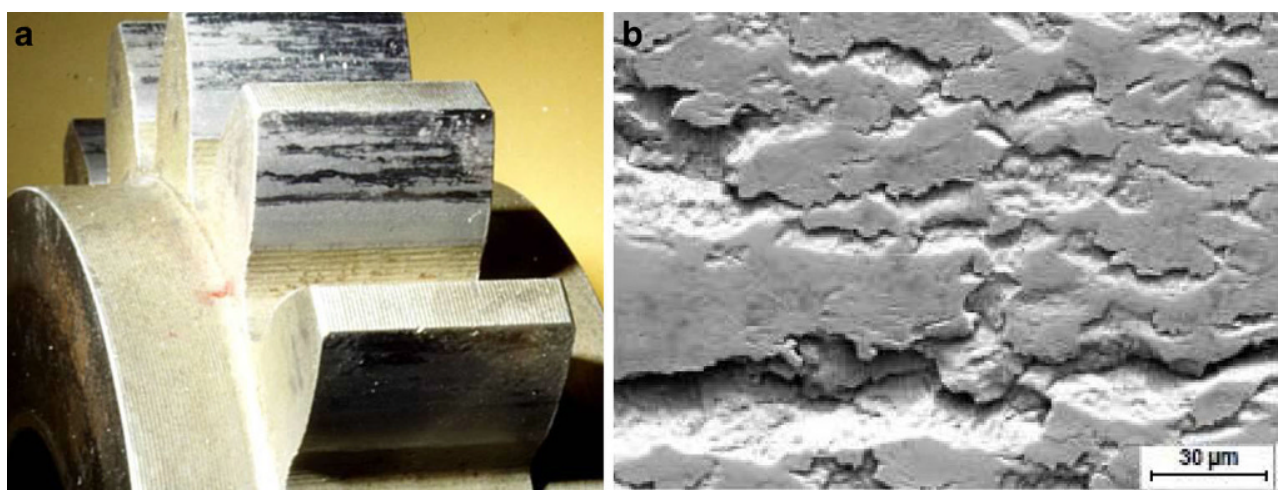
plications on the test results and the use of the material 18CrNiMo7-6, which is often used especially for larger gears in many industrial applications, for the test gears were examined. The results were obtained during the research project FVA 779 [4]. The objective of this paper is to share these experimental results and to show the suitability of the test results for modern practical gear applications.

\section{State of the art}

Micropitting occurs under highly loaded conditions in Hertzian type of rolling and sliding contact under lubrication regimes in EHL-contacts, especially in mixed lubrication regim. It can be detected commonly on materials with high surface hardness and is the result of numerous small surface cracks, and is therefore a surface fatigue phenomenon [1].

Micropitting occurs primarily in the area of negative specific sliding. The area of negative specific sliding on gears is located below pitch point $\mathrm{C}$ on the line of action of the pinion and wheel. The area above pitch point $\mathrm{C}$ is the area of positive sliding [1]. The characteristic crack orientation near the surface is found to be against the direction of sliding and is visualized for a driving pinion in Fig. 1a [5, 6]. Fig. 1b shows a microscope-image of a micropitted surface with surface cracks.

Clarke et al. [6] investigated the plastic deformation which takes place during the initial stage of the running-in of gears and its effect on micropitting. It was shown that significant residual effects occur, which can contribute to an early formation of surface-initiated cracks [6].

When micropitting occurs, cracks near the surface will terminate or grow back to the surface, which will lead to small material outbreaks. These outbreaks are typically $10 \mu \mathrm{m}$ to $20 \mu \mathrm{m}$ deep and change the profile form. These outbreaks appear as a grey and dull coherent area on affected surfaces [7].

Fig. 2 shows a micropitted gear flank and a $950 \times$ magnification of a part of this area.

As running time increases, micropitting can spread over the entire tooth flank. The resulting scouring generally reduces the quality of the gearing. Furthermore, the additional dynamic forces and the noises of the gears increase. Last but not least, micropitting can lead to pitting damage [7]. The influence of micropitting on the appearance of pitting was investigated comprehensively in [8-10].

Further recent research on the topic of micropitting, especially concerning practical applications, can be found here [11-13].

The main parameters influencing the appearance of micropitting can be classified according to Schrade [1] into three groups, which are operating conditions, the lubricant used and the condition of the surface of the mating contact partners. Operating conditions include load, operating temperature and circumferential speed. The influence of the lubricant can be divided into a system consisting of base oil and additive and the nominal viscosity [1].

It should be noted that the performance of the lubricant regarding micropitting resistance is highly depending on operating conditions if the lubricant contains additives. The influence of additive chemistry on micropitting is further discussed in [14].

Vrcek et al. [15] also showed that micropitting and wear damage are highly case-dependent. It can be found that PAO-based engine oil tends to eliminate micropitting damage compared to mineral-based engine oil under less severe lubricating conditions.

Because of the strong effect of the additives on micropitting load-carrying capacity, the load-carrying capacity of gear lubricants has to be determined by physical testing under suitable test conditions. In addition to the established test method according to FVA 54/7 [2], which is also described in DIN 3990-16 [3], other test methods, for example according to Flender [16], ZF-WP [17] ZF-NPittingtest [18] and PAE [19] are used.

The result of the micropitting test according to FVA 54/7 [2] can be used for calculating a reference value for the determination of the safety factor against micropitting of a gear-lubricant-system according to ISO/TS 633622 [20]. Since micropitting occurs under unfavorable lubrication conditions, the lubricant film thickness is used as important parameter in the calculation method according

\section{Micropitting test $\mathrm{C} / 8.3 / 90$}

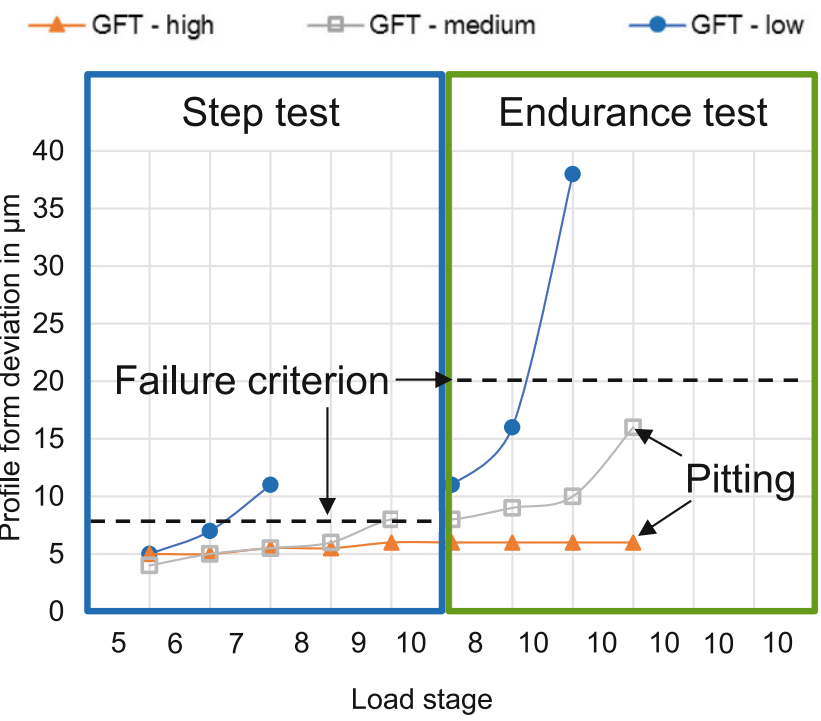

Fig. 3 Exemplary test runs using lubricants with different levels of micropitting load capacity [32] 
Table 1 Torque on pinion $\mathrm{T}_{1}$ for each load stage and the corresponding Hertzian contact pressure at pitch point pC for micropitting test according to FVA $54 / 7$

\begin{tabular}{llllllll}
\hline Load stage & Running-in & 5 & 6 & 7 & 8 & 9 & 10 \\
\hline $\mathrm{T}_{1}$ in $\mathrm{Nm}$ & 28.2 & 70 & 98.9 & 132.5 & 171.6 & 215.6 & 265.1 \\
$\mathrm{P}_{\mathrm{c}}$ in $\mathrm{N} / \mathrm{mm}^{2}$ & 510.0 & 795.1 & 945.1 & 1093.9 & 1244.9 & 1395.4 & 1547.3 \\
\hline
\end{tabular}

to ISO/TS 6336-22. Since the surface of the mating contact partner and especially surface roughness have a great influence on the occurrence of micropitting, initial surface roughness is also included in the calculation according to ISO/TS 6336-22 [20]. Further calculation methods are available, for example according to Barnett et al. [21] or Walkowiak [22].

Because of the great importance of surface roughness to micropitting, several recent studies on this topic are available. Bell et al. [23] investigated different surface roughness parameters which are available to characterize components such as gears or bearings. Another roughness parameter $3_{\text {o50 }}$ was utilized in this research to characterize especially superfinished or honed surfaces. Prajapati et al. [24] also conducted an experimental investigation of the evolution of surface damage and topography parameters during rolling contact fatigue tests.

Beside surface roughness, the surface of the mating contact partners is influenced by gear size, gear geometry, finishing method and gear material [1].

In some practical applications, for example in wind turbines, the gears are larger than the test gears used in research on micropitting [7, 25].

The transferability of the conclusions on micropitting on medium-sized gears (e.g., as used in FVA 54/7) to large gearboxes was comprehensively and successfully shown in [26-31].

In modern applications the material $18 \mathrm{CrNiMo} 7-6$, profile modifications and profile grinding are used for the gears. In addition, helical gears are commonly used. The influence on the result of the micropitting test according to FVA 54/7 of using test gears designed under consideration of practical applications has not yet been extensively studied.

\section{Materials and methods}

In the following, the procedure for the micropitting test according to FVA 54/7 [2] and the experimental setup of the test rig are described. Additionally, the materials used and the the test gear geometry are documented.

\subsection{Micropitting test method according to FVA 54/7}

The micropitting test according to FVA 54/7 [2] is a test method to evaluate the micropitting capacity of gear lubri- cants which also allows a comparison of different lubricants. Additionally, the test result can be used for the calculation of the micropitting load capacity of a given gear drive, for example according to ISO/TS 6336-22 [20].

"The micropitting test according to FVA-Information Sheet 54/7 consists of two parts and is carried out for a specific oil under fixed conditions with respect to oil temperature and circumferential speed. First, a step test for predefined load stages with increasing torque is performed. The result of this step test is a classification of the lubricant with respect to the micropitting load capacity expressed as a failure load stage (SKS). This SKS-value is defined as the load stage at which the defined failure criterion (profile form deviation $\mathrm{f}_{\mathrm{fm}}$ ) is exceeded. In a second part, a subsequent endurance test usually is performed which provides information about the progress of micropitting at a higher number of load cycles" [32].

Fig. 3 visualizes the test procedure and shows exemplary test results for lubricants with different levels of micropitting load capacity in the standard test. The averaged maximum profile form deviation over the load stages and the failure criterions can also be seen.

Table 1 shows the torque on pinion $T_{1}$ for each load stage and the corresponding Hertzian contact pressure at pitch point $\mathrm{p}_{\mathrm{C}}$, which is used in the micropitting test according to FVA 54/7 [2]. Table 2 shows the standard test conditions for the micropitting test according to FVA 54/7 [2].

Table 2 Standard test conditions in the micropitting test according to FVA-Information Sheet [2]

\begin{tabular}{llll}
\hline Dimension & Symbol & Value & Unit \\
\hline Pinion speed & $n_{1}$ & 2250 & $\mathrm{rpm}$ \\
Circumferential speed & $v$ & 8.3 & $\frac{m}{s}$ \\
Driving gear & - & Pinion & - \\
Oil inlet temperature & $\vartheta$ Oil & $90 \pm 2$ & ${ }^{\circ} \mathrm{C}$ \\
$\begin{array}{l}\text { Running time during run- } \\
\text { ning-in }\end{array}$ & - & 1 & Hours \\
$\begin{array}{l}\text { Running time per load stage } \\
\text { Running time per inspection }\end{array}$ & - & 16 & Hours \\
interval in endurance test & - & 80 & Hours \\
Lubrication & - & Spray lu- & - \\
& & brication & \\
\hline
\end{tabular}




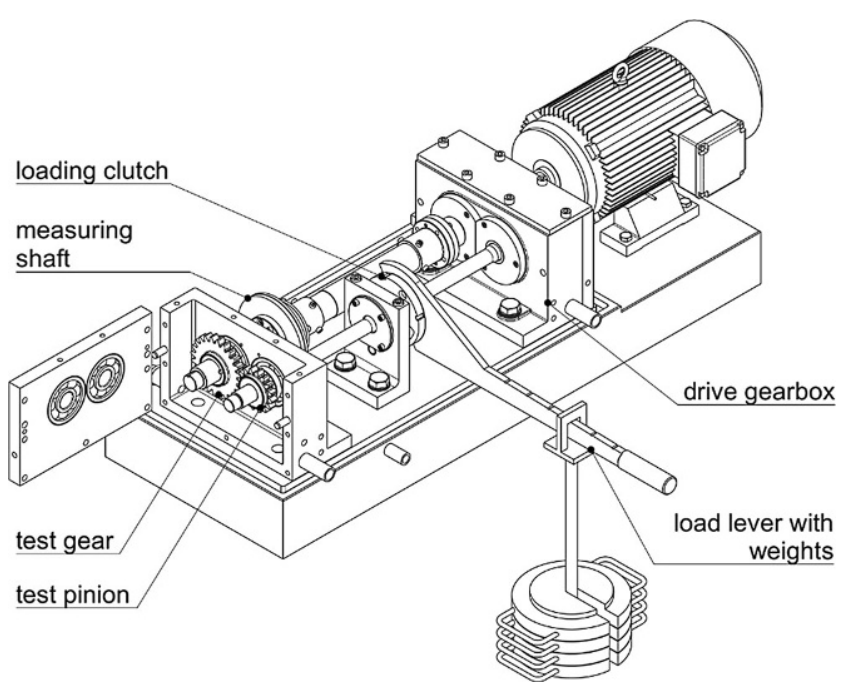

Fig. 4 Schematic illustration of the mechanical layout of the FZG back-to-back test rig according to ISO 14635-1 [33]

\subsection{Experimental setup of the FZG back-to-Back test rig}

The micropitting test according to FVA 54/7 [2] is conducted on a FZG back-to-back test rig according to ISO 14635-1 [33]. Fig. 4 shows the schematic design of the test rig. "The test rig consists of test gears and slave gears with an identical gear transmission ratio. The test gears and the slave gears are connected through two torsional shafts. The pinion of the test gear and the pinion of the slave gear are mounted on the same shaft, and the wheel of the slave gear and the wheel of the test gears are located on the other shaft. The shaft between the pinions is divided into two parts that are connected by a coupling. While this coupling is opened at standstill, one coupling flange is fixed and the other flange is loaded with a lever and weights to introduce a static torque into the system. After the coupling is locked, the lever is removed and the electric motor can be started. Different weights are hung on the loading arm to adjust the defined torque. The motor only has to compensate the power losses in the system, which allows very energy-efficient testing" [34].

For the micropitting test according to FVA 54/7 [4] the test gears are running spray lubricated at a fixed lubricant temperature which is controlled thermostatically by a temperature sensor and electric heating elements in the test gearbox housing.

\subsection{Materials of the used test gears}

The materials $16 \mathrm{MnCr} 5$ (as reference) and $18 \mathrm{CrNiMo} 7-6$ (as alternative) were used in this research. The test gears were case-hardened and manufactured as defined in the specifications of the micropitting test according to FVA 54/7 [2]. According to Information sheet FVA 54/7, the material $16 \mathrm{MnCr} 5$ is used for the standard reference test gears. Therefore, the test gears with $16 \mathrm{MnCr} 5$ are the reference. Table 3 and 4 show the chemical composition of $16 \mathrm{MnCr} 5$ and $18 \mathrm{CrNiMo} 7-6$ according to chemical analysis at the research center and the specifications of the nominal values according to steel key [35].

\subsection{Geometry of the used test gears}

The "FZG-C" test gears type "C-GF" are used for the micropitting test according to FVA 54/7. Details of this type of gearing are summarized in Table 5.

The test gears used in the micropitting test according to FVA 54/7 [2] are designed as spur gears without any tooth correction. The flank surfaces of the test gears are finished by Maag $0^{\circ}$-grinding, a grinding process which allows the manufacture gears of high and constant quality but is meanwhile hardly used in practical application. Especially for

Table 3 Chemical composition of $16 \mathrm{MnCr} 5$ according to chemical analysis at the research center. Specifications of the nominal values according to steel key [35]

\begin{tabular}{lllllllllll}
\hline 16MnCr5 & \multicolumn{1}{l}{ Chemical composition, mass percentage in \% } & & & & \\
(1.7131) & $\mathrm{C}$ & $\mathrm{Si}$ & $\mathrm{Mn}$ & $P$ & $\mathrm{~S}$ & $\mathrm{Cr}$ & $\mathrm{Mo}$ & $\mathrm{Ni}$ & $\mathrm{Al}$ & $\mathrm{Cu}$ \\
\hline Actual value & 0.150 & 0.226 & 1.068 & 0.009 & 0.023 & 1.029 & 0.051 & 0.205 & 0.028 & 0.254 \\
Specification [35] & $0.14-0.19$ & $\mathrm{Max}$. & $1.00-1.30$ & Max. & Max. & $0.8-1.1$ & - & - & - & - \\
& & 0.40 & & 0.025 & 0.035 & & & & & \\
\hline
\end{tabular}

Table 4 Chemical properties of 18 CrNiMo7-6 according to chemical analysis at the research center. Specifications of the nominal values according to steel key [35]

\begin{tabular}{|c|c|c|c|c|c|c|c|c|c|c|}
\hline \multirow{2}{*}{$\begin{array}{l}18 \mathrm{CrNiMo} 7-6 \\
(1.6587)\end{array}$} & \multicolumn{10}{|c|}{ Chemical composition, mass percentage in $\%$} \\
\hline & $\overline{\mathrm{C}}$ & $\mathrm{Si}$ & $\mathrm{Mn}$ & $P$ & $\mathrm{~S}$ & $\mathrm{Cr}$ & Mo & $\mathrm{Ni}$ & $\mathrm{Al}$ & $\mathrm{Cu}$ \\
\hline Actual value & 0.180 & 0.152 & 0.554 & 0.010 & 0.011 & 1.589 & 0.250 & 1.468 & 0.024 & 0.108 \\
\hline $\begin{array}{l}\text { Specification } \\
\text { [35] }\end{array}$ & $0.15-0.21$ & $\begin{array}{l}\text { Max. } \\
0.40\end{array}$ & $0.50-0.90$ & $\begin{array}{l}\text { Max. } \\
0.025\end{array}$ & $\begin{array}{l}\text { Max. } \\
0.035\end{array}$ & $1.50-1.80$ & $0.25-0.35$ & $1.40-1.70$ & - & - \\
\hline
\end{tabular}


Table 5 Details of type "FZG-C" test gears for the FZG micropitting test [2]

\begin{tabular}{llll}
\hline Dimension & Symbol & $\begin{array}{l}\text { Numerical } \\
\text { value }\end{array}$ & Unit \\
\hline $\begin{array}{l}\text { Center distance } \\
\text { Effective tooth }\end{array}$ & $\mathrm{a}$ & 91.5 & $\mathrm{~mm}$ \\
width & $\mathrm{b}$ & 14.0 & $\mathrm{~mm}$ \\
$\begin{array}{l}\text { Module } \\
\text { Number of teeth, }\end{array}$ & $\mathrm{m}$ & 4.5 & $\mathrm{~mm}$ \\
pinion & $z_{1}$ & 16 & - \\
$\begin{array}{l}\text { Number of teeth, } \\
\text { wheel }\end{array}$ & $z_{2}$ & 24 & - \\
$\begin{array}{l}\text { Pressure angle } \\
\text { Helix angle }\end{array}$ & $\alpha$ & 20.0 & $\circ$ \\
$\begin{array}{l}\text { Mean roughness of } \\
\text { pinion and wheel }\end{array}$ & Ra & 0 & $\circ$ \\
Tooth correction & Without tip relief and root relief, no longitu- \\
& dinal crowning & HV1 \\
$\begin{array}{l}\text { Surface hardness } \\
\text { Material }\end{array}$ & $\begin{array}{l}750 \pm 30 \\
\text { 16MnCr5 (case-hardened) }\end{array}$ \\
\hline
\end{tabular}

larger gears, the profile grinding process is frequently used in modern applications instead. In addition, the gears are usually manufactured with profile modifications to reduce the influence of premature meshing. Furthermore, helical gears are often used in modern gear boxes.

For this purpose, test gears for this study were designed under consideration of practical applications. Hence, the variants I, II, III and IV, which show some changes compared to the test gears of type C-GF used in FVA 54/7 [2] were defined. Table 6 shows the changes in the variants compared to the reference (C-GF).

All of the variants were finished by profile grinding. For variants I, II and III the macro-geometry was the same as the test gears of type "C-GF". Variant I additionally has a tip edge rounding on pinion $\rho_{\mathrm{K} 1}$ and wheel $\rho_{\mathrm{K} 2}$. On Variant III tip relief on the pinion $\mathrm{C}_{\mathrm{a} 1}=30 \mu \mathrm{m}$ and the wheel $\mathrm{C}_{\mathrm{a} 2}=35 \mu \mathrm{m}$ was applied. Variant IV was manufactured as a helical gear set with the same pitch cylinder as the gears of type "C-GF" in order to derive a comparable helical gear from a spur gear according to Stahl [36]. The profile modifications of the helical gears (Variant IV) were carried out under consideration of practical applications with tip relief on pinion and wheel and longitudinal crowning on the pinion.

\section{Results}

In this research, tests with case-hardened gears of the materials $16 \mathrm{MnCr} 5$ and $18 \mathrm{CrNiMo} 7-6$ were conducted to investigate if the results from the micropitting test obtained with reference test gears made out of $16 \mathrm{MnC} 5$ can be transferred to gears made out of $18 \mathrm{CrNiMo} 7-6$. Additionally, the influence of test gears designed under consideration of practical applications on the test results is presented. All tests were carried out with a circumferential speed of $\mathrm{v}_{\mathrm{t}}=8.3 \mathrm{~m} / \mathrm{s}$ at pitch point and an oil temperature $\vartheta_{\text {Oil }}=90^{\circ} \mathrm{C}$. The lubricant used during all tests was the reference oil FVA $3 \mathrm{~A}$, which is a mineral oil with ISO-VG 100 and a medium micropitting load capacity $(\mathrm{SKS}=9)$ under reference test conditions.

\subsection{Influence of the material}

In order to investigate the influence of the material on test results three tests with $16 \mathrm{MnCr} 5$ and three tests with 18CrNiMo7-6 were conducted. Fig. 5 shows the average profile deviation of all tests during the testing. The usual manufacturing-related deviations can be seen in the new state. After load stage 5, micropitting occurs with resulting profile form deviations of approx. 3 to $5 \mu \mathrm{m}$ for all tests. The profile form deviations increased continuously during load stages 5 to 8 respectively 9 for all test runs. After load stage 8 , the profile form deviations are between 6 and approximately $8 \mu \mathrm{m}$. For all tests, the course of the profile form deviations shows comparable characteristics. In test run "18CrNiMo7-6 test 1", the failure criterion was exceeded shortly after load stage 9. As a result, the test was continued in load stage 10. During load stage 10, a noticeable increase in the profile deviations was observed. The main characteristics of the profile form deviations of the gears made out of material $18 \mathrm{CrNiMo7}-6$ were comparable to gears made out of the material $16 \mathrm{MnCr} 5$. This can

Table 6 Changes in the test gear variants I, II, III and IV compared to C-GF (reference)

\begin{tabular}{llllll}
\hline Dimension & C-GF & I & II & III & IV \\
\hline Helix angle $\beta$ & 0 & 0 & 0 & 0 & $27.44^{\circ}$ \\
Grinding & Maag $0^{\circ}-$ & Profile- & Profile- & Profile- & Profile- \\
Tooth correction & None & $\rho_{\mathrm{K} 1}=35 \mu \mathrm{m} \rho_{\mathrm{K} 2}=60 \mu \mathrm{m}$ & None & $\mathrm{C}_{\mathrm{a} 1=30 \mu \mathrm{m}}$ & $\mathrm{C}_{\mathrm{a} 1 / 2=40 \mu \mathrm{m}}$ \\
& & & & $\mathrm{C}_{\mathrm{a} 2}=35 \mu \mathrm{m}$ & $\mathrm{C}_{\mathrm{b} 1=5 \mu \mathrm{m}}$ \\
Key: & & Indeces: & 1: Pinion \\
$\rho_{\mathrm{K}}:$ Amount of tip edge rounding & & 2: Wheel & \\
$\mathrm{C}_{\mathrm{a}}:$ Amount of tip relief & & & \\
$\mathrm{C}_{\mathrm{b}}:$ Amount of longitudinal crowning & & & \\
\hline
\end{tabular}




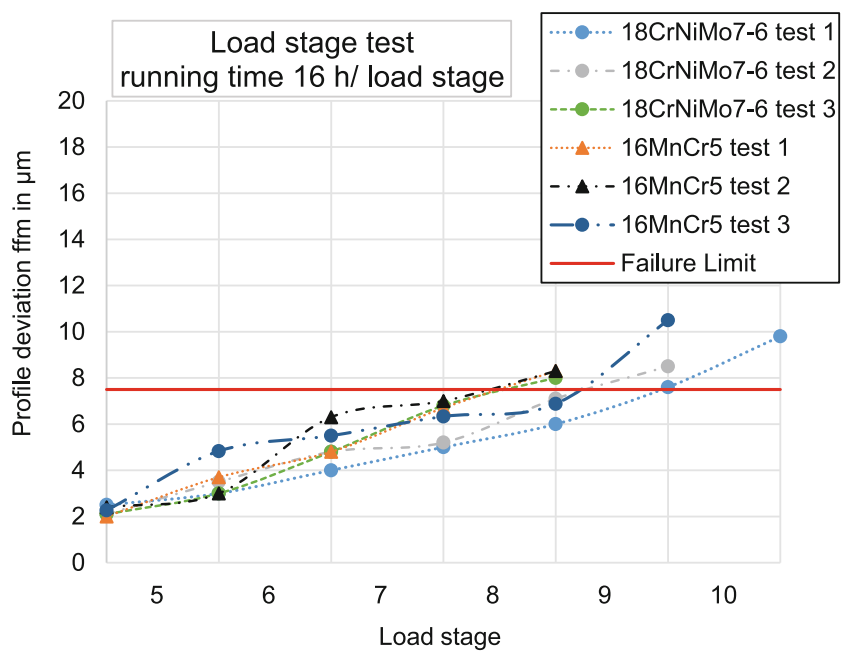

Fig. 5 Profile deviation of all test runs "Influence of the material"

be seen for one tooth of one pinion after load stage 8 in Fig. 6 exemplary. The scouring starts for both materials in all tests in the beginning of the line of action and grows up to the pitch point. The micro-pitted area and mass loss increased according to the average profile deviation and showed no difference between the gears of $16 \mathrm{MnCr} 5$ and 18CrNiMo7-6. The micro-pitted area was detected as a coherent area below the pitch point for both materials. Fig. 7 shows exemplary the flanks of the pinions of one test with $16 \mathrm{MnCr} 5$ and one test with $18 \mathrm{CrNiMo} 7-6$.

In the test runs with $18 \mathrm{CrNiMo} 7-6$ a failure load stage (SKS) of 8 was detected once; twice the test results indicated $\mathrm{SKS}=9$. In the test runs with $16 \mathrm{MnCr} 5$ a failure load stage (SKS) of 8 was detected twice; and once the test results indicated SKS $=9$. The repeatability of the test method according to the state of knowledge is one load stage. The profile deviation, micro-pitted area and mass loss of all test runs indicate a medium micro-pitting load capacity (GFTmedium). Consequently, all tests showed comparable results. Table 7 summarizes the test results and also shows mean roughness $\mathrm{Ra}$ of the pinion and wheel of each test.

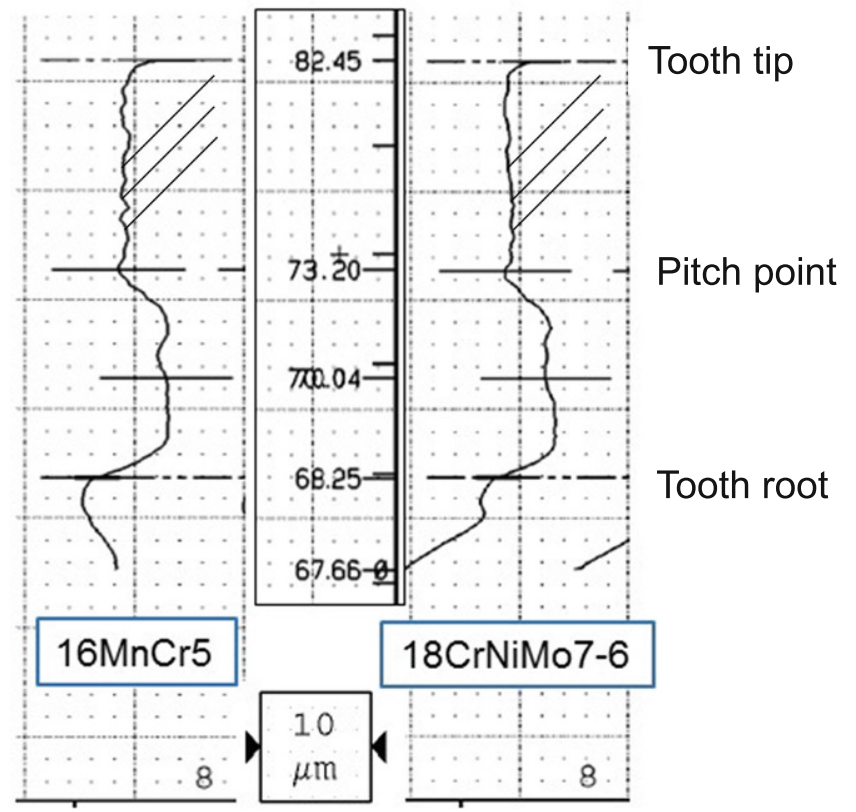

Fig. 6 Exemplary measurement of the profile form of one tooth of the pinion after load stage 8 for $16 \mathrm{MnCr} 5$ and $18 \mathrm{CrNiMo} 7-6$

\subsection{Influence of the test gear geometry and grinding process}

One step test and one endurance test were carried out with the type "C-GF" test gears and the test gears of variants I, II, III and IV. All test gears for these investigations were made out of refence material $16 \mathrm{MnC} 5$. In order to generate comparable conditions during the experiments with variant IV, the torque on the pinion was adjusted for every load stage, which resulted in similar values for the Hertzian pressure at the pitch point and minimum lubricant film thickness compared with the type "C-GF" test gears.

Fig. 8 shows the average profile deviation of all test runs determined with the different test gears. The usual manufacturing-related deviations can be seen in the new state. The profile deviations of all variants increase continuously over the test duration and consistently exceed the failure criterion of $\mathrm{f}_{\mathrm{fm}}=7.5 \mu \mathrm{m}$ after load stage 9 in the load stage
Fig. 7 Exemplary pictures of pinion flanks after load stage 8 with the materials $16 \mathrm{MnCr} 5$ (a) and $18 \mathrm{CrNiMo7}-6$ (b)
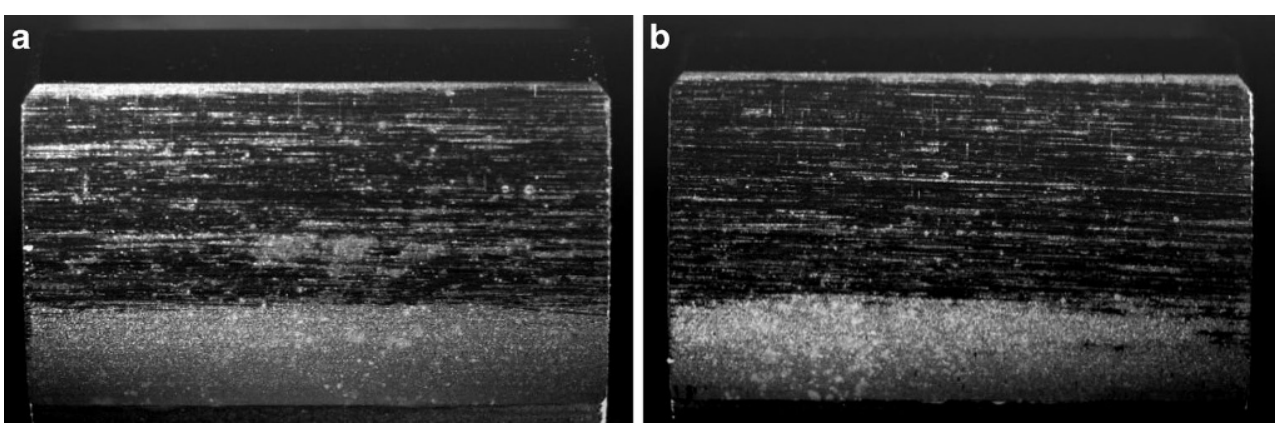
Table 7 Overview of the mean roughness and test results with gears of different materials

\begin{tabular}{lllllll}
\hline Test & 1.1 & 1.2 & 1.3 & 2.1 & 2.2 & 2.3 \\
\hline Material & $18 \mathrm{CrNiMo7-6}$ & $18 \mathrm{CrNiMo} 7-6$ & $18 \mathrm{CrNiMo7}-6$ & $16 \mathrm{MnCr} 5$ & $16 \mathrm{MnCr} 5$ \\
Ra & $0.49 \mu \mathrm{m}$ & $0.47 \mu \mathrm{m}$ & $0.54 \mu \mathrm{m}$ & $0.52 \mu \mathrm{m}$ & $0.52 \mu \mathrm{m}$ & $0.56 \mu \mathrm{m}$ \\
SKS & 9 & 9 & 8 & 8 & 8 & 9 \\
GF-Class & Medium & Medium & Medium & Medium & Medium & Medium \\
\hline
\end{tabular}

test. The profile deviations of variant III, variant IV and the type "C-GF" test gears are clearly above the failure criterion of $7.5 \mu \mathrm{m}$. The values of variants I and II are close to the failure criterion of $7.5 \mu \mathrm{m}$. Nevertheless, a failure load stage of 9 could be confirmed for all 4 variants. In the endurance run, similar characteristics were also found for all runs. Although not all variants achieved the same running time in the endurance test, the results can be considered comparable within the usual test scatter.

Fig. 9 shows the measurement results of the profile form after the endurance test for all variants. For all variants, it can be seen that the scouring starts in the beginning of the line of action and grows up to the pitch point. For variants III and IV, the maximum scouring is shifted somewhat further away from the beginning of the line of action towards the pitch point due to the profile modifications. The micro-pitted area and mass loss increased according to the average profile deviation and showed no difference between the different test gears. In the endurance test, a scrape-mark close to the beginning of the tooth contact on the pinion flank could be detected during the test run with variant II. Fig. 10 shows the micro-pitted area on the pinions after the end of the load stage test and Fig. 11 shows the micropitted area on the pinions after the end of the endurance test. The micro-pitted area was detected as a coherent area below the pitch point for all test gears during the load stage test. During the endurance test, micropitting could also be detected above the pitch point. The micro-pitted areas were comparable for all test gears.

According to the average profile deviation, micro-pitted area and mass loss a medium micro-pitting load capacity (GFT - medium) was determined. Table 8 shows an overview of the test results and mean roughness of pinion and wheel.

\section{Discussion}

Investigations were carried out with test gears made out of case-hardened materials $16 \mathrm{MnCr} 5$ and $18 \mathrm{CrNiMo} 7-6$. It could be shown that the trends in the increase in average profile deviation, micro-pitted area and mass loss over the test are equivalent for all carried out tests. For the lubricant used here a medium micropitting load capacity (GFTmedium) was determined for each test. The scatter of the results can be considered low. Consequently, no significant difference could be found between the two materials $16 \mathrm{MnCr} 5$ and $18 \mathrm{CrNiMo7}-6$. This result confirms the results of Schönnenbeck [7] and Lützig [27]. In addition, this corresponds to the current state of knowledge on pitting load-carrying capacity. Finally, it can be stated from the results that the base material is of secondary importance

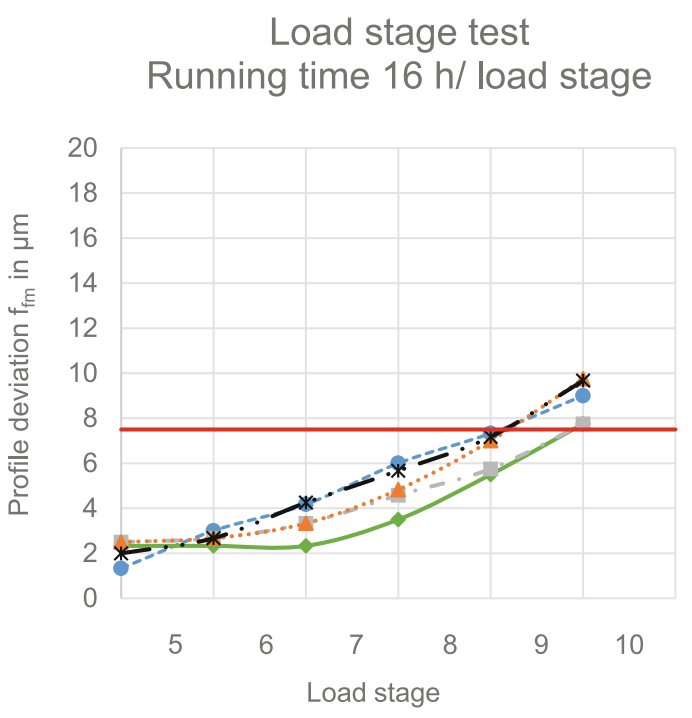

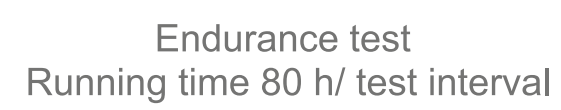

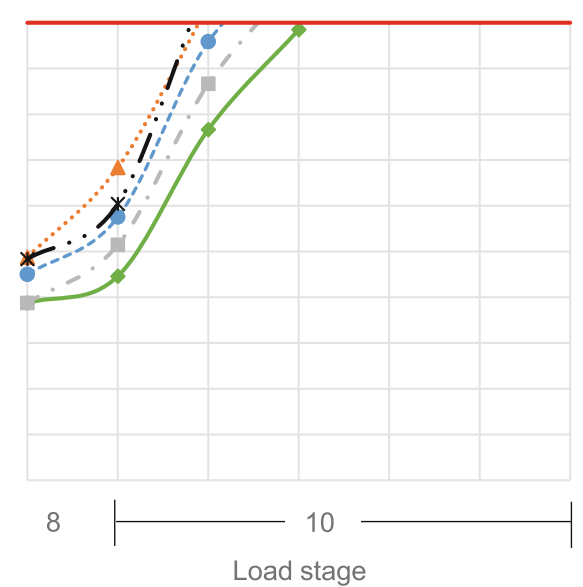

Test Conditions: $n_{1}=22501 / \mathrm{min}$ $\vartheta_{\text {Oil }}=90^{\circ} \mathrm{C}$ $R_{a} \approx 0.5 \mu \mathrm{m}$ Lubricant: FVA3A

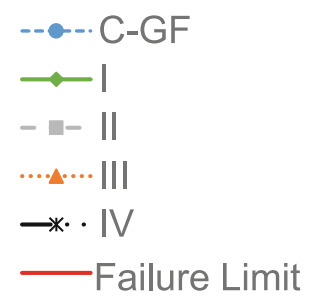

Fig. 8 Profile deviations of all test runs "Influence of the test gears" 


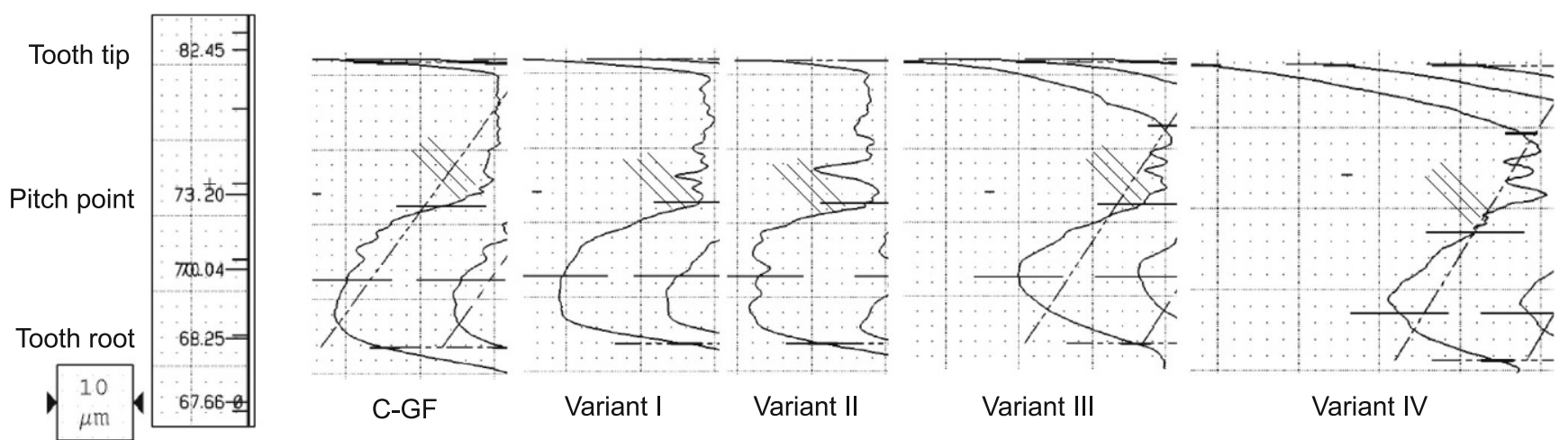

Fig. 9 Exemplary measurement of the profile form of one tooth of the pinion after the endurance test for different test gears

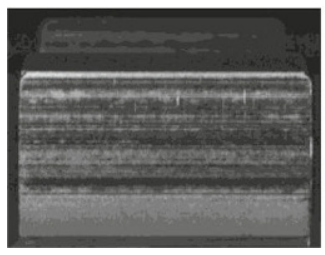

C-GF

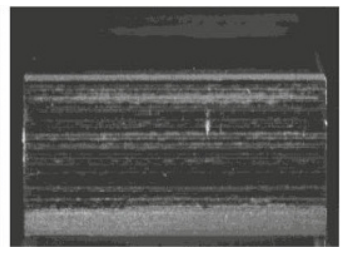

Variant I

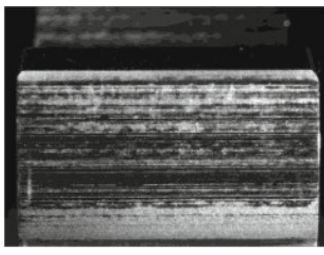

Variant II

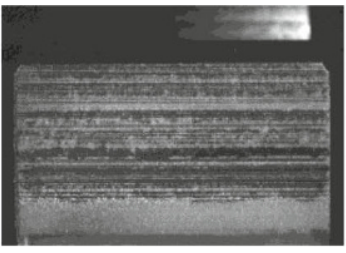

Variant III

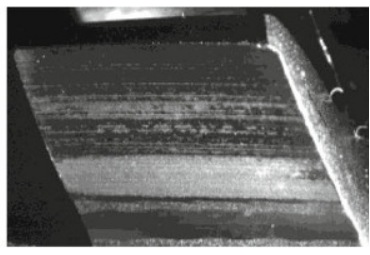

Variant IV

Fig. 10 Exemplary pictures of pinion flanks after the end of the load stage test of different test gears

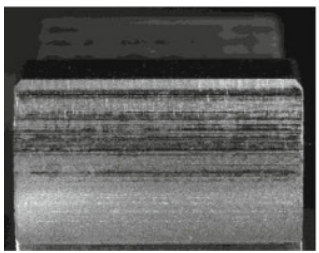

C-GF

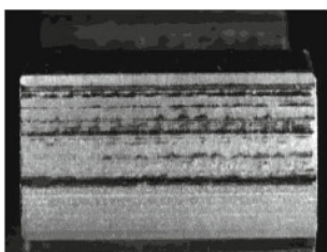

Variant I

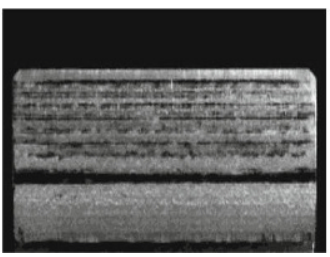

Variant II

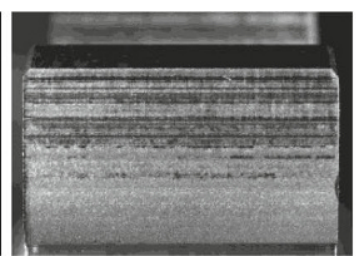

Variant III

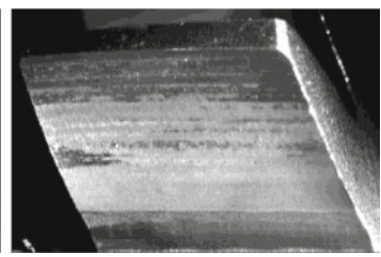

Variant IV

Fig. 11 Exemplary pictures of pinion flanks after the end of the endurance test of different test gears

as long as comparable material properties are present after heat treatment. In particular, comparable surface properties (material hardness, components and structure, etc.) must be present for comparable micropitting load-carrying capacity. In order for the results of the micropitting test according to FVA 54/7 [2] to be suitable for practical gear application, a comparable material condition must be present after heat treatment according to the state of the art. In this case, the lubricant characteristics determined in the micropitting test according to FVA 54/7 can be transferred to a lubricantgear concept with the tested lubricant and gears made out of the widely used material 18CrNiMo7-6.
In addition, a load stage test and an endurance test were carried out with each of the type "C-GF" test gears and the test gears of variants I, II, III and IV. Variants I, II, III and IV were designed under consideration of practical applications. All variants and type "C-GF" test gears showed comparable trends in the increase in average profile deviation, micro-pitted area and mass loss over the test. For each variant and test gears type "C-GF," the scouring caused by micropitting was mainly located below the pitch point. For variants III and IV, the maximum scour was shifted further away from the beginning of the line of action and towards the pitch point due to the profile modification. The extent

Table 8 Overview of the mean roughness and test results with different test gears

\begin{tabular}{llllll}
\hline Test & 4.1 & 5.1 & 6.1 & 7.1 & 8.1 \\
\hline Variant & C-GF & I & II & III & IV \\
Mean roughness Ra & $0.53 \mu \mathrm{m}$ & $0.58 \mu \mathrm{m}$ & $0.53 \mu \mathrm{m}$ & $0.49 \mu \mathrm{m}$ & $0.50 \mu \mathrm{m}$ \\
SKS & 9 & 9 & 9 & 9 & 9 \\
GF-Class & Medium & Medium & Medium & Medium & Medium \\
\hline
\end{tabular}


of maximum profile deviation is nevertheless comparable for all variants and type "C-GF" test gears. When the variants I, II, III and IV were used, a medium micropitting load capacity and SKS $=9$ could be determined for the reference lubricant FVA 3A. This equals the result of the standardized micropitting test method according to FVA 54/7 [2], which requires the use of type "C-GF" test gears. Taking into account all damage-typical parameters, the results can be seen as equivalent. The results show that, when the grinding process is changed from MAAG- $0^{\circ}$ grinding to profile grinding, no significant effect on the test result is to be expected. This confirms the results of research project FVA 259/II-III [37]. A profile modification of type "C-GF" test gears by tip edge rounding or tip relief does not indicate any significant influence on the test result on the basis of the tests carried out here. The use of helical gears under the same conditions with regard to Hertzian pressure and minimum lubricant film thickness also has no effect on the test result in the micropitting test according to FVA 54/7. This shows that the calculation method according to ISO/TS 6336-22 [20] corresponds well with the application. It should be noted that the use of oils with a higher micropitting resistance may lead to a influence on the test results due to a reduction in premature meshing and occurrence of a scrape mark.

\section{Conclusion}

The results show that the following practical changes in the micropitting test according to FVA 54/7 have no significant influence on the test result:

- Use of the material $18 \mathrm{CrNiMo7}-6$

- Use of profile modifications on test gears oriented to practical applications

- Use of profile grinding of the test gears

- Use of helical gears under the same conditions with regard to pressure and minimum lubricant film thickness

As a result, the suitability of the results of the micropitting test according to FVA 54/7 for modern gear applications were proven. An adaptation of the test method is not necessary, since no significant influence on the result is to be expected.

The presented results are of great importance for users of the results from the micropitting test. Hence, this research answers important questions which were intensively discussed in the past regarding the applicability and transferability of results from the standardized micropitting test for different industrial applications. It can be stated that the micropitting test according FVA 54/7 respectivly DIN 399016 delivers reliable results with regard to the discrimination of the micropitting performance of different gear lubricants also for gears in modern gearboxes.

Funding Open Access funding enabled and organized by Projekt DEAL.

Conflict of interest N. Sagraloff, T. Tobie and K. Stahl declare that they have no competing interests.

Open Access This article is licensed under a Creative Commons Attribution 4.0 International License, which permits use, sharing, adaptation, distribution and reproduction in any medium or format, as long as you give appropriate credit to the original author(s) and the source, provide a link to the Creative Commons licence, and indicate if changes were made. The images or other third party material in this article are included in the article's Creative Commons licence, unless indicated otherwise in a credit line to the material. If material is not included in the article's Creative Commons licence and your intended use is not permitted by statutory regulation or exceeds the permitted use, you will need to obtain permission directly from the copyright holder. To view a copy of this licence, visit http://creativecommons.org/licenses/by/4. $0 /$.

\section{References}

1. Schrade U (1999) Influence of gear geometry and operating conditions on the micropitting load-carrying capacity of gears (in German). PhD Thesis, Technical University of Munich, Munich, Germany

2. Schönnenbeck G, Emmert S (1993) FVA-Nr. 54/I-IV-Micro-pitting information sheet: test procedure for the investigation of the micro-pitting capacity of gear lubricants. Forschungsvereinigung Antriebstechnik e. V., Frankfurt a.M.

3. DIN Deutsches Institut für Normung e. V. (2020) Calculation of load capacity of cylindrical gears-Part 16: Determination of the micro-pitting load-carrying capacity of lubricants using FZG-testmethod GT-C/8.3/90 (Mai 2020)

4. Sagraloff N, Tobie T, Stahl K (2020) FVA No. 779/I-Micro-pitting application test-final report. Forschungsvereinigung Antriebstechnik e.V., Frankfurt a.M. (in German)

5. Brecher C, Klocke F (2017) Gear and transmission technology. Design, manufacture, investigation, simulation. Hanser, Munich (in German)

6. Clarke A, Evans HP, Snidle RW (2016) Understanding micropitting in gears. J Mech Eng Sci 230:1276-1289

7. Schönnenbeck G (1984) Influence of lubricants on tooth flank fatigue (micropitting and pitting) mainly in the circumferential speed range $1 . . .9 \mathrm{~m} / \mathrm{s}$ (in German). $\mathrm{PhD}$ Thesis, Technical University of Munich, Munich, Germany

8. Felbermaier M (2018) Investigations on micropitting and its influence on the pitting load capacity of case-hardened cylindrical gears (in German). PhD Thesis, Gear Research Center (FZG), Technical University of Munich

9. Hergesell M (2012) Micropitting and pitting of case-hardened gears of medium and small size (in German). PhD Thesis, Technical University of Munich, Munich, Germany

10. König J (2020) Increase in tooth flank carrying capacity through optimized manufacturing and lubrication (in German). PhD Thesis, Technical University Munich 2020

11. Oila A, Shaw BA, Aylott CJ, Bull SJ (2005) Martensite decay in micropitted gears. Proc Inst Mech Eng Part J J Eng Tribol 219:77-83

12. McGuire N (2019) Lubrication challenges in the wind turbine industry. Tribol Lubr Technol 2019:34-43

13. Morales-Espejel GE, Rycerz P, Kadiric A (2017) Prediction of micropitting damage in gear teeth contacts considering the concurrent 
effects of surface fatigue and mild wear. Wear 1-52. https://doi.org/ 10.1016/j.wear.2017.11.016

14. O'Connor B (2005) The influence of additive chemistry on micropitting. In: Gear Technology, Chicago, USA Mai/June 2005, pp 35-41

15. Vrcek A, Hultqvist T, Baubet Y, Björling M, Marklund P, Larsson R (2019) Micro-pitting and wear assessment of PAO vs mineral-based engine oil operating under mixed lubrication conditions: effects of lambda, roughness lay and sliding direction. lubricants

16. Flender FBV-VST (1997) Determination of the micro-pitting resistance of gear oils in the single-stage test-Test method and evaluation (in German). report GG-V, vol 378 (Rev.-No. 1)

17. Litzba J, Boeye J (2012) Determination of the micropitting loadcarrying capacity of oils for wind turbine gearboxes at low circumferential speeds. GETLUB, Würzburg

18. Joachim FJ, Kessler A, Kurz N, Rother F (2004) Practice-oriented gear tests for lubricant testing. 14th International Colloquium Tribology, Friedrichshafen

19. Rother S, Kurz A, Bick (2002) PAE-/FZG-Micropittingtest C-GF/8,3/ 90-20

20. International Organization for Standardization (2018) ISO/TS 6336-22:2018-04, Calculation of load capacity of spur and helical gears-Part 22: Calculation of micropitting load capacity. Geneva, Switzerland (2018-04)

21. Barnett D, Elderkin JP, Bennett W (2006) An analytical approach to the prediction of micro-pitting on case carburised gears. American Gear Manufacturers Association,

22. Walkowiak M (2013) Local loads and wear simulation in the tooth meshes of profile-corrected spur and helical gears between the start of deflection and the end of deflection (in German). PhD Thesis, Ruhr University Bochum

23. Bell M, Sroka G, Benson R (2013) The effect of the roughness profile on micropitting. Gear Solut 2013:47-53

24. Prajapati DK, Tiwari M (2020) Experimental investigation on evolution of surface damage and topography parameters during rolling contact fatigue tests. Fatigue Fract Eng Mater Struct 2020:355-370

25. Emmert S (1994) Investigation of tooth flank fatigue (micropitting, pitting) of high-speed spur gears (in German). PhD Thesis, Technische University München

26. Nazifi K (2010) Influence of geometry and operating conditions on micropitting of large gearboxes. PhD Thesis, Ruhr University Bochum
27. Lützig G, Predki W (2006) FVA No. 286/II-Micropitting load-carrying capacity of large gearboxes II-final report. Forschungsvereinigung Antriebstechnik e.V., Frankfurt a.M. (in German)

28. Lützig G (2007) Large gearboxes-micropitting: influence of flank modification and surface roughness (in German)

29. Lohmann C (2016) Correlation of fatigue, cracking, wear and micropitting load capacity on cylindrical gears. PhD Thesis, RuhrUniversity Bochum

30. Predki W, Nazifi K, Luetzig G (2010) Micropitting of big gearboxes: influence of flank modification and surface roughness. In: VDI International Conference on Gears

31. Haske D (2000) FVA-Nr. 2861 - Heft 633 - Großgetrieben Abschlussbericht

32. Sagraloff N, Hein M, Tobie T, Stahl K (2017) Practical use of micropitting test results according to FVA 54/7 for calculation of micropitting load capacity according to ISO/TR 15144-1. In: Proceedings of the ICG International Conference on Gears 13.09.2017, Garching, Germany

33. DIN Deutsches Institut für Normung e. V. (2006) DIN ISO 146351: 2006-05, Gears - FZG test methods Part 1: FZG test method A/8.3/90 for determining the relative scuffing load capacity of lubricating oils (in German)

34. Sagraloff N, Dobler A, Tobie T, Stahl K, Ostrowski J (2019) Development of an oil free water-based lubricant for gear applications. Lubricants 7(4):33-10

35. Wegst M, Wegst CW (2016) Stahlschlüssel-Key to Steel, 24th edn. Verlag Stahlschlüssel Wegst, Marbach

36. Stahl K (2000) Pitting load capacity of case-hardened spur and helical gears especially considering the pressure distribution (in German). PhD Thesis, Technical University Munich

37. Liu W (2003) Influence of different manufacturing processes on the micropitting load-carrying capacity of gears (in German). PhD Thesis, Technical University of Munich, Munich, Germany

Nadine Sagraloff research associate

Thomas Tobie head of department

Karsten Stahl full professor 